\title{
Volumetric change of flowable composite resins due to polymerization as measured with an electronic mercury dilatometer
}

Riaan Mulder*, Sias R Grobler and Yusuf I Osman

*Correspondence: drriaanmulder@gmail.com

Oral and Dental Research Institute, Faculty of Dentistry, University of the Western Cape, Cape Town, South Africa.

\begin{abstract}
Background: To determine the total volumetric change and the relative speed of shrinkage of bulk fill flowable composites during polymerization.

Materials and methods: A specially designed electronic mercury dilatometer was used to determine the volumetric change. The light intensity was $500 \mathrm{~mW} / \mathrm{cm}^{2}$. The mercury dilatometer measured the volumetric change every 0.5 seconds during the 35 second irradiation exposure time. The materials tested were Z250 as standard and control. Four bulk fill flowable composites were tested.

Results: The sequence of total volumetric change was found to be: Z250 < Filtek bulk fill $<$ Xtra-Base bulk fill $<$ SDR $<$ Venus bulk fill. The speed of shrinkage of the bulk fill flowables was faster than that of Z250, while the 2 flowables with the highest shrinkage speed (SDR and Venus) also had the highest total volumetric change. Of the different materials tested the volumetric change of Z250 (1.13\%) was the lowest and significantly less ( $\mathrm{p}<0.05)$ than that of SDR $(1.55 \%)$ and Venus $(1.72 \%)$. The material with the highest filler content (Z250) also showed the lowest shrinkage (1.13\%) but this effect could not be seen in the flowables. In general, it was found that a 35 second irradiation period (with a light intensity of $500 \mathrm{~mW} / \mathrm{cm}^{2}$ ) was satisfactory for complete polymerization of the resins.

Conclusions: The volumetric changes and speed of shrinkage were higher for all 4 bulk fill flowable composites than for Z250. SDR and Venus flowables had the fastest and highest volumetric shrinkage.

Clinical significance: The manufacturers of bulk fill flowable composites advocate filling layers of $4 \mathrm{~mm}$. However, because of the high shrinkage values found in this study it should be suggested that the standard $2 \mathrm{~mm}$ layer increments still be used.

Keywords: Volumetric change, flowable composites, mercury dilatometer, polymerization, bulk fill
\end{abstract}

\section{Introduction}

During polymerization the distance between groups of atoms/ molecules decreases with a resultant volume change that is known as shrinkage [1-3]. Polymerization shrinkage as low as $2 \%$ in composites may generate enough tension to destroy the marginal integrity between the restoration and the tooth structure which could result in micro-leakage, post-operative sensitivity and/or the failure of the restoration [4-6].

However, to minimize volumetric shrinkage, dental material manufacturers previously advised placing composite resins in increments not larger than $2-3 \mathrm{~mm}$ before it is polymerized. Nowadays, manufacturers are becoming bolder with suggested increments of up to $4 \mathrm{~mm}$ in regard to the bulk fill flowable composites [7-11]. This method of placement of bulk fill flowable composites, could pose a problem if the shrinkage of the material is too large and allows the disruption of the integrity of the tooth-restoration interface.

Various techniques are available to measure the volumetric change which occurs during irradiation with a curing light [12-15]. An electronic mercury dilatometer proved to be accurate in measuring polymerization shrinkage $[1,12-18,35,39]$. The volumetric shrinkage measured by the electronic mercury dilatometer is linear and the volumetric change is measured as the total percentage shrinkage that occurred between the preand post-gel phases. Examples of various volumetric measuring techniques are the mercury dilatometer, water dilatometer, linear techniques and the pycnometer. A disadvantage with the utilization of dilatometers is that they are extremely sensitive to variations in temperature $[14,19]$. Oberholzer et al., [15] described a specially designed electronically controlled mercury dilatometer which measured change in volume of the sample every 0.5 seconds.

Studies were completed on varying irradiation techniques to decrease polymerization shrinkage and polymerization stress. Some of these techniques resulted in a low initial conversion rate of the organic matrix. However, the moment the resin material became rigid, the internal stresses and polymerization stress started to increase $[\mathbf{8 , 2 0}$. It has been established that exposures not higher than $500 \mathrm{~mW} / \mathrm{cm}^{2}$, were able to provide a sufficient combination of irradiance and exposure time [15,21]. It was found that conversion rate resulting in carbon double bond formation can range from $55-75 \%$ under conventional irradiation conditions of $500 \mathrm{~mW} / \mathrm{cm}^{2}[22,23]$.

In an attempt to decrease volumetric shrinkage, an increase 


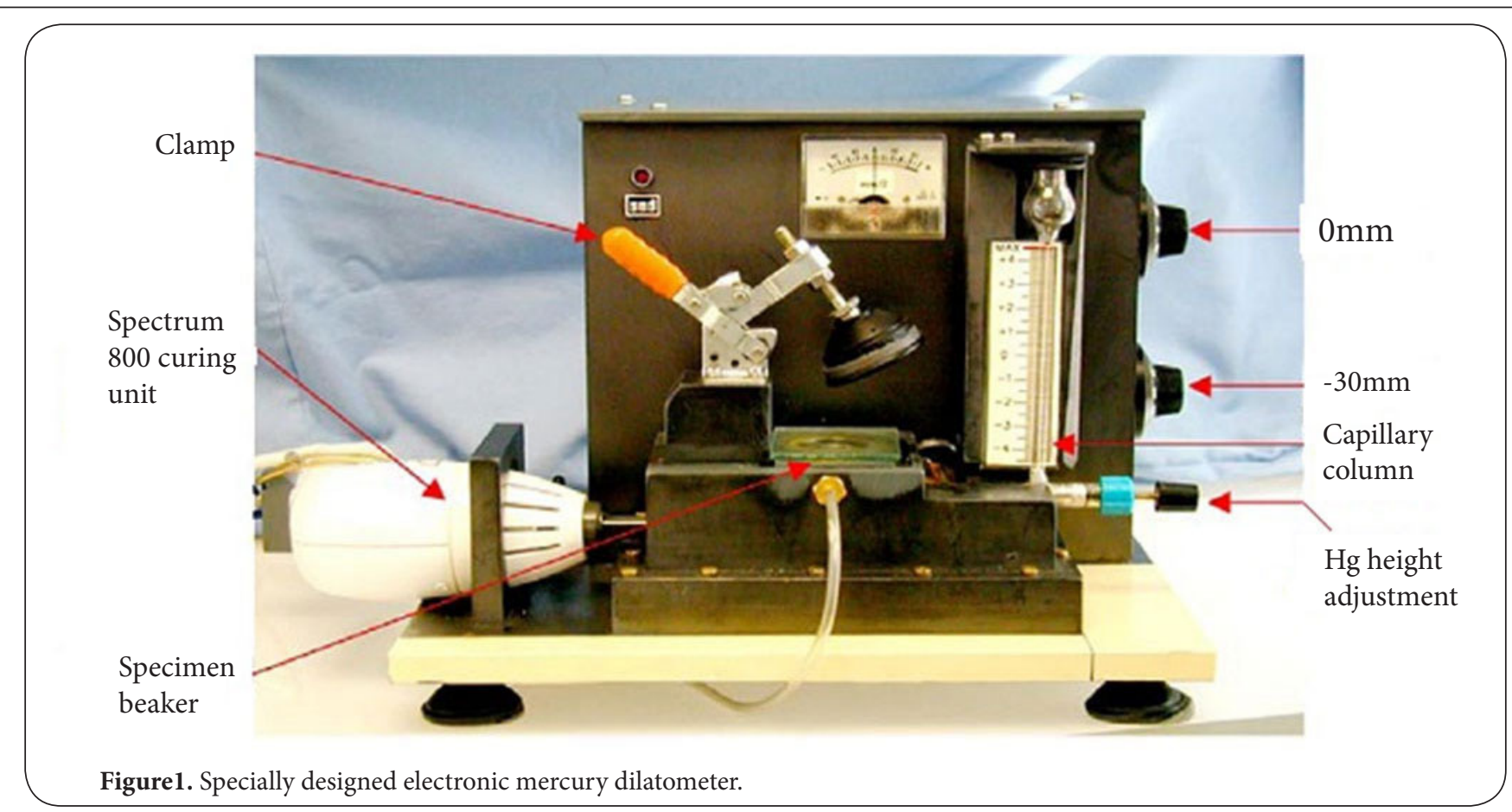

in the molecular weight of the organic matrix was suggested [24-27]. Furthermore, by increasing the filler content the resulting contraction stress that developed was found to be directly proportional to the filler content regardless of the matrix $[20,28]$. Therefore, the purpose of this study was to determine the relative volumetric change and the speed of shrinkage of bulk fill flowable composites relative to the composite Z250.

\section{Materials and methods}

The composite Z250 by 3M ESPE (Massachusetts, USA) was used as the standard control material. Furthermore, the shrinkage over time of four newly developed bulk fill flowable composites was measured.

The bulk fill flowable composites consisted of Smart Dentin Replacement (SDR) by Dentsply/Caulk (Milford, Germany), Venus bulk fill by Haraeus Kulzer (Hanau, Germany), Filtek bulk fill flow by 3M ESPE (Massachusetts, USA) and Xtra base bulk fill flowable by Voco (Cuxhaven, Germany). Volumetric change was measured with a specially designed electronic mercury dilatometer (Figure 1) [15] .The volumetric change due to polymerization in the dental resin material is measured as a voltage change by a pressure sensitive transducer. An analog to digital converter creates data that is transmitted from the pressure sensor to RS232 format - where the computer creates a graph of volumetric change in Microsoft Excel, From the data collected every 0.5 seconds over the 35 seconds from the curing light irradiation period the graph has time in seconds on the X-axis and the percentage of volumetric change on the $\mathrm{Y}$-axis. All samples were cured for 35.0 seconds at $500 \mathrm{~mW} / \mathrm{cm}^{2}$ with a Dentsply/Caulk Spectrum 800 halogen curing light in order to standardize the curing process. The output was monitored with a Caulk (Milford, Germany) radiometer to ensure $500 \mathrm{~mW} / \mathrm{cm}^{2} \pm 50 \mathrm{~mW} / \mathrm{cm}^{2}$. Calibration of the modified mercury dilatometer was done prior to every specimen test. Ten sample specimens of each material were tested. The Teflon specimen holder has a hole with a diameter of $5.0 \mathrm{~mm}$ and a height of $2.5 \mathrm{~mm}$ resulting in the specimen volume in the Teflon holder of $49.087 \mathrm{~mm}^{3}$. Briefly, the specimen was placed in the dilatometer and the clamp closed. The calibration was achieved by adjusting the mercury column. The curing light was activated by the computer when the mercury dilatometer had a stable environment for 5.0 seconds. The polymerization shrinkage of the resin material and the resultant volumetric change was measured every 0.5 seconds. The dilatometer was kept in a temperature controlled incubator at the $25^{\circ} \mathrm{C} \pm 1^{\circ} \mathrm{C}$ [29]. The baseline effect of the curing unit was established prior to each set of experimental set-ups and the data corrected accordingly [21]. This correction resulted in the volumetric shrinkage that is presented for each material to be the true volumetric change due to polymerization only. Therefore only the effect of polymerization shrinkage from a monomer to a polymer remained $[21,29,30]$.

\section{Results}

The total volumetric change for all ten samples of each material was presented as a combination in the Box and Whisker plot (Figure 2). Each Box and Whisker plot gives the maximum and minimum values. The intermediary box gives the range of $50 \%$ of the values and the solid line in each box indicates the median value for the 10 samples. The sequence of total volumetric change according to the shrinkage values 

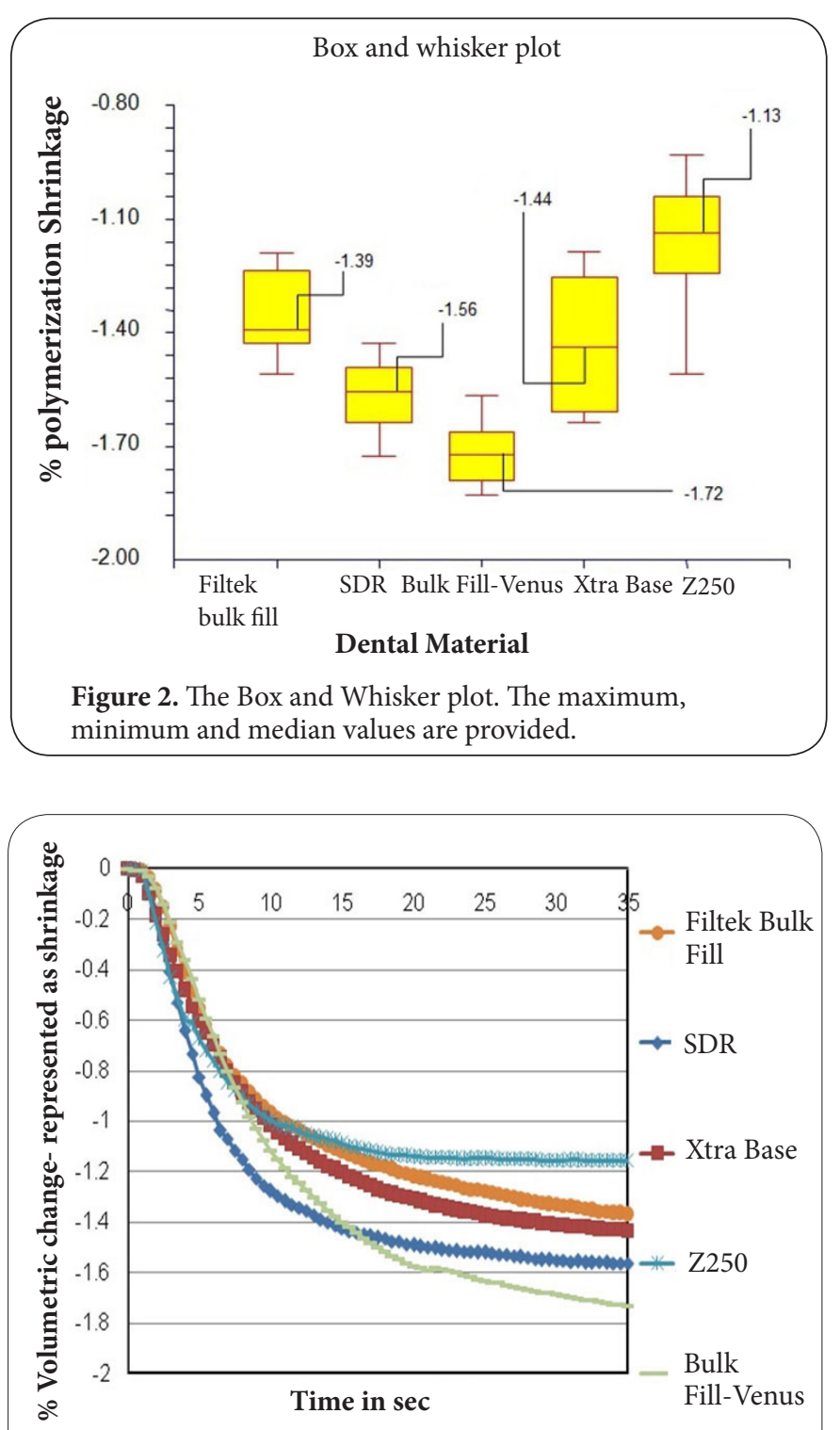

Figure 3. Volumetric change over a 35 second irradiation period (an average of 10 samples per material).

after 35 seconds was: Z250< Filtek $<$ Xtra base $<$ SDR $<$ Venus. The Kruskal-Wallis multiple-comparison test was used to show statistical significant differences in the total volumetric change amongst materials. The results (Figure 2) indicated that SDR and Venus bulk fill had significantly more volumetric shrinkage compared to Z250. Z250 shrank 1.13\% and Venus bulk fill had the largest volumetric shrinkage of $1.72 \%$.

The Tukey-Kramer multiple comparison test on the rate of shrinkage slopes (Figure 3 ) showed that at a 1.5-5.0 second time period, the slope of SDR was significantly $(p<0.05)$ steeper (shrank the fastest) than that of all the other materials. At the time slot (5.5-20.0 seconds) Venus shrank the fastest (steepest slope). For the 20.5-25.0 period Z250 shrank significantly slower than Filtek, Venus and Xtra base but not significantly slower than SDR. When the polymerization rate (slope) of Z250 was considered for the time period 20.5-30.0 seconds, it was found that the rate of polymerization shrinkage of all the bulk fill flowable composites tested were statistically significantly faster than that of Z250.

\section{Discussion}

Oberholzer et al., developed the dilatometer used in this study [15]. The main advantage of the dilatometer was that the change of the mercury height in the capillary could be measured electronically, instead of manual viewing. Furthermore, the electronic dilatometer enables measurements to be made on samples regardless of their shape and size. It was concluded [15] that the exothermic reaction from the small sample used was negligible and did not affect the volumetric change. The additional volumetric change that occurs due to the light source could also be determined and the real volumetric change calculated.

From the literature many factors might have an influence on the volumetric shrinkage of a material i.e., filler content, filler size, type of monomers, monomer content, organic matrix and type, and organic matrix conversion factors. The highest percentage volumetric shrinkage (Figure 3) for all 5 materials occurred approximately within the first 10.0 seconds. Furthermore, it can be seen that most ( 90\%) of the polymerization shrinkage for all 5 different materials took place in the first 20 seconds and the degree of polymerization was generally completed after 35 seconds of constant irradiation. Davidson [12] also reported that $90 \%$ of the shrinkage of composites took place during the first 20 seconds. However, when the sequence of shrinkage (Filtek $<$ Xtra base $<$ SDR $<$ Venus) of the 4 bulk flowables was compared to their filler content (Table 1) no clear trend could be seen. Furthermore, the sizes of the fillers alone (Table 1) did not seem to show a clear effect on the shrinkage values, although Z250 with an average filler size of $0.6 \mu \mathrm{m}$ showed a lower shrinkage $(1.16 \%)$ relative to SDR with a higher average filler size of $4.2 \mu \mathrm{m}$. Unfortunately, the average filler sizes of the other flowables were not stipulated by the manufacturers and their possible effects on shrinkage could not be discussed. In general, the rate of polymerization shrinkage (Figure 3) for all the bulk fill flowable composites was faster than the control composite Z250.

The literature also showed that in general the higher the monomer content and the more flowable, the higher the shrinkage [12,25,31-35] and the faster the conversion rate to the gel phase $[18,20,22]$. Again, without the necessary information (Table 1) this could not be meaningfully discussed. The shrinkage curve (Figure 3) for Venus over the whole 35 second period was the most fluent which indicated a steady shrinkage which might have a positive effect on bond strength.

The slopes of the shrinkage rates over the first 5 seconds did not differ significantly. However, over the 5-15 second period, Venus and SDR shrank the fastest after which period 
Mulder et al. Oral Biology and Dentistry 2013,

http://www.hoajonline.com/journals/pdf/2053-5775-1-1.pdf

doi: $10.7243 / 2053-5775-1-1$

Table 1. Information on the various resin composites and \% volumetric shrinkage found.

\begin{tabular}{|c|c|c|c|c|c|}
\hline Dental material & Inorganic filler & Organic resin matrix & Filler size $\mu \mathrm{m}$ & $\%$ filler wt. & Shrinkage \\
\hline $\begin{array}{l}\text { Z250 (3M ESPE) Lot } 176833 \\
\exp 2013-05\end{array}$ & Zirconia/ silica & $\begin{array}{l}\text { bisGMA }(1-10 \%), \text { UDMA }(1-10 \%) \text {, } \\
\text { BisEMA }(1-10 \%), \text { TEGDMA }(<5 \%)\end{array}$ & $\begin{array}{l}0.01-3.5 \\
\text { (Average size } 0.6)\end{array}$ & 78 & $1.13 \%$ \\
\hline $\begin{array}{l}\text { SDR bulk flow (Dentsply/ } \\
\text { Caulk) Lot 110429. exp. } \\
\text { 2013-04 }\end{array}$ & $\begin{array}{l}\text { Barium-alumino-fluoro- } \\
\text { borosilicate glass; } \\
\text { Strontium alumino-fluoro- } \\
\text { silicate glass }\end{array}$ & $\begin{array}{l}\text { SDR patented urethane }(<25 \%) \text {, } \\
\text { TEGDMA }(<10 \%) \text {, EPBADMA } \\
(<10 \%)\end{array}$ & Average size 4.2 & 68 & $1.55 \%$ \\
\hline $\begin{array}{l}\text { Venus Bulk Fill (Haraeus Kul- } \\
\text { zer) Lot } 010031 \text { exp. 2014-08 }\end{array}$ & $\begin{array}{l}\text { barium- alumina-fluoro- } \\
\text { silicate, } \\
\text { YbF3, Silica. }\end{array}$ & $\begin{array}{l}\text { UDMA (Not available), EPBADMA } \\
\text { (Not available) }\end{array}$ & $0.02-5$ & 65 & $1.72 \%$ \\
\hline $\begin{array}{l}\text { Filtek bulk flow (3M ESPE) lot } \\
\text { N356852 exp. 2015-02 }\end{array}$ & $\begin{array}{l}\text { YBF3 filler } \\
\text { Zirconia / silica }\end{array}$ & $\begin{array}{l}\text { UDMA }(10-20 \%) \text {, bisGMA }(1-10 \%) \text {, } \\
\text { bisEMA (6) (1-10\%), procrylat resins } \\
(10-20 \%), \text { TEGDMA }(<1 \%)\end{array}$ & $\begin{array}{l}0.1-5 \\
0.01-3.5\end{array}$ & 64.5 & $1.39 \%$ \\
\hline $\begin{array}{l}\text { Xtra Base bulk flow (Voco) Lot } \\
1201096\end{array}$ & $\begin{array}{l}\text { Not available from manu- } \\
\text { facturer }\end{array}$ & bisGMA (10-25\%), UDMA (10-25\%) & Not available & 75 & $1.44 \%$ \\
\hline
\end{tabular}

Table 2. Molecular weight of individual monomers.

\begin{tabular}{ll}
\hline Resin present in material & $\begin{array}{l}\text { Molecular } \\
\text { weight g/mol }\end{array}$ \\
\hline UDMA (urethane dimethacrylate) & 470.55 \\
SDR-UDMA & 849 \\
TEGDMA3 (6-dioxaoctamethylene-dimethacrylate) & 286.32 \\
bisGMA (bis-phenol glycidylmethacrylate) & 512.59 \\
$\begin{array}{l}\text { Bisema6 (bisphenol A polyethylene glycol diether } \\
\text { dimethacrylate). }\end{array}$ & 496.58 \\
$\begin{array}{l}\text { EBADMA (2-propenoic acid 2-methyl- } \\
\text { 1,1'-[(1-methylethylidene) bis(4,1-phenylene- } \\
\text { oxy-2,1-ethanediyl)] ester }\end{array}$ & 496.58 \\
$\begin{array}{l}\text { EPBADMA } \\
\begin{array}{l}\text { Procrylate2,2-bis[4-(3-methacryloxypropoxy) } \\
\text { phenyl]propane }\end{array}\end{array}$ \\
\hline
\end{tabular}

they all levelled out to about the same slope and shrinkage rate. After about 15 seconds the shrinkage rate of SDR decreased at which stage Venus began to shrink at a faster rate than SDR. The speed of shrinkage (slopes) of the other 2 bulk flowables (Xtra-Base and Filtek) was about the same with Xtra-Base ending marginally higher total volumetric shrinkage value. Therefore it can be seen that the two materials (SDR and Venus) with the fastest polymerization rates (highest slopes) also had the largest total volumetric shrinkage. Our shrinkage value obtained for Z250 (1.13\%) corresponds well with other published values of $1.1 \%[21,33,36-39]$.

The ratio of the viscous base monomer to the more flowable diluent monomers has also been found to be a large contributing factor to the percentage of polymerization shrinkage [40]. However, in this study the influence that the ratio might have on the volumetric change, could unfortunately not be sensibly discussed as the manufacturers of the dental materials did not provide the exact ratio or percentage of different monomers contained in the dental materials (Table 1). By combining various monomers to create a multifunctional organic matrix - a reduction of polymerization shrinkage and water sorption can be achieved [40].

It was also reported that the higher the molecular weight of a molecule (Table 2) the lower the shrinkage [24-27], but when there are variations in the mixtures of chemicals with different molecular weights and in different ratios (like the flowables tested in this study) it would not be possible to illustrate clear trends.

Despite all the above-mentioned factors which might have varying influences on the speed and volume of shrinkage, this study proved that the only reliable way to establish and compare the performance of the materials is by measuring the volumetric shrinkage.

\section{Conclusion}

Differences in the volumetric change amongst all four bulk fill flowable composites were found. However, the technical brochures on the bulk fill flowable composites advocate filling increments of $4 \mathrm{~mm}$ layers. All the bulk fill flowable composites had a volumetric shrinkage greater than that of the Z250 control. Therefore, it can be concluded that it would be advisable to place layers of $2 \mathrm{~mm}$ increments.

\section{Competing interests}

The authors declare that they have no competing interests.

\section{Authors' contributions}

R Mulder: conceived idea, methodology, experiments. SR Grobler, YI Osman: Supervision and assistance in the write-up of the literature review, discussion, statistical results.

\section{Acknowledgement}

This study forms part of an MSc study. It was partly supported by the IADR and the C. H. Pameijer Fellowship.

Publication history

EIC: Thimios A. Mitsiadis, University of Zurich, Switzerland. Senior Editor: Mutlu Özcan, University of Zurich, Switzerland. Received: 06-Jul-2013 Revised: 31-Jul-2013

Accepted: 31-Jul-2013 Published: 08-Aug-2013 
Mulder et al. Oral Biology and Dentistry 2013,

http://www.hoajonline.com/journals/pdf/2053-5775-1-1.pdf

doi: $10.7243 / 2053-5775-1-1$

\section{References}

1. Loshaek $S$ and Fox TG. Factors influencing the efficiency of cross-linking in co-polymers of methyl methacrylates and glycol methacrylates. J Am Chem Soc. 1953; 75:3297-3614. | Article

2. Patel MP, Braden $M$ and Davy KW. Polymerization shrinkage of methacrylate esters. Biomaterials. 1987; 8:53-6. | Article | PubMed

3. Venhoven BA, de Gee AJ and Davidson CL. Polymerization contraction and conversion of light-curing BisGMA-based methacrylate resins. Biomaterials. 1993; 14:871-5. | Article | PubMed

4. Abbas G, Fleming GJ, Harrington E, Shortall AC and Burke FJ. Cuspal movement and microleakage in premolar teeth restored with a packable composite cured in bulk or in increments. J Dent. 2003; 31:437-44. | Article | PubMed

5. Alomari QD, Reinhardt JW and Boyer DB. Effect of liners on cusp deflection and gap formation in composite restorations. Oper Dent. 2001; 26:406-11. | Article | PubMed

6. Meredith $\mathrm{N}$ and Setchell DJ. In vitro measurement of cuspal strain and displacement in composite restored teeth. J Dent. 1997; 25:331-7. | Article | PubMed

7. Filtek bulk fill flowable operation manual. | Website

8. Scientific Compendium SDR - 2011. I Website

9. Venus operation manual. | Website

10. Voco operation manual. | Website

11. 2250 operation manual. | Website

12. Davidson CL and Feilzer AJ. Polymerization shrinkage and polymerization shrinkage stress in polymer-based restoratives. J Dent. 1997; 25:435-40. | Article | PubMed

13. de Gee AF, Feilzer AJ and Davidson CL. True linear polymerization shrinkage of unfilled resins and composites determined with a linometer. Dent Mater. 1993; 9:11-4. | Article | PubMed

14. Lai JH and Johnson AE. Measuring polymerization shrinkage of photoactivated restorative materials by a water-filled dilatometer. Dent Mater. 1993; 9:139-43. | Article | PubMed

15. Oberholzer TG. A modified dilatometer for determining volumetric polymerization shrinkage of dental materials. Meas Sci Technol. 2001; 13:78-83. | Article

16. Attin T, Buchalla W, Kielbassa AM and Helwig E. Curing shrinkage and volumetric changes of resin-modified glass ionomer restorative materials. Dent Mater. 1995; 11:359-62. | Article | PubMed

17. Puckett $A D$ and Smith R. Method to measure the polymerization shrinkage of light-cured composites. J Prosthet Dent. 1992; 68:56-8. I Article I PubMed

18. Rueggeberg $F$ and Tamareselvy K. Resin cure determination by polymerization shrinkage. Dent Mater. 1995; 11:265-8. | Article | PubMed

19. Penn RW. A recording dilatometer for measuring polymerization shrinkage. Dent Mater. 1986; 2:78-9. | Article | PubMed

20. Silikas N, Eliades $\mathrm{G}$ and Watts DC. Light intensity effects on resincomposite degree of conversion and shrinkage strain. Dent Mater. 2000; 16:292-6. | Article | PubMed

21. Oberholzer TG, Grobler SR and Rossouw RJ. [Polymerization shrinkage by 4 different types of dental materials]. SADJ. 2001; 56:513-6. | PubMed

22. Stansbury JW and Dickens SH. Network Formation and Compositional Drift during Photo- Initiated Copolymerization of Dimethacrylate Monomers. Polymer 2001; 42:6363-9. | Article

23. Baroudi K, Saleh AM, Silikas N and Watts DC. Shrinkage behaviour of flowable resin-composites related to conversion and filler-fraction. $J$ Dent. 2007; 35:651-5. | Article | PubMed

24. Braga RR, Ballester RY and Ferracane JL. Factors involved in the development of polymerization shrinkage stress in resin-composites: a systematic review. Dent Mater. 2005; 21:962-70. | Article | PubMed

25. Condon JR and Ferracane JL. Assessing the effect of composite formulation on polymerization stress. J Am Dent Assoc. 2000; 131:497-
503. | Article | PubMed

26. Cramer NB, Stansbury JW and Bowman CN. Recent advances and developments in composite dental restorative materials. J Dent Res. 2011; 90:402-16. | Article | PubMed Abstract | PubMed Full Text

27. Ferracane JL and Greener EH. The effect of resin formulation on the degree of conversion and mechanical properties of dental restorative resins. J Biomed Mater Res. 1986; 20:121-31. | Article | PubMed

28. Chen HY, Manhart J, Hickel R and Kunzelmann KH. Polymerization contraction stress in light-cured packable composite resins. Dent Mater. 2001; 17:253-9. | Article | PubMed

29. Jin X, Bertrant L and Hammesfahr PD. (DENTSPLY/L. D. Caulk Division, Milford, DE, USA). Effect of heat expansion and contraction on polymerization shrinkage measurement by mercury dilatometer. IADR/ AADR/CADR 80th General Session (March 6-9, 2002). I Website

30. Halvorson RH, Erickson RL and Davidson CL. Energy dependent polymerization of resin-based composite. Dent Mater. 2002; 18:463-9. | Article | PubMed

31. Ge J, Trujillo $M$ and Stansbury J. Synthesis and photopolymerization of low shrinkage methacrylate monomers containing bulky substituent groups. Dent Mater. 2005; 21:1163-9. | Article | PubMed

32. Goldman M. Polymerization shrinkage of resin-based restorative materials. Aust Dent J. 1983; 28:156-61. | Article | PubMed

33. Goncalves F, Kawano $Y$ and Braga RR. Contraction stress related to composite inorganic content. Dent Mater. 2010; 26:704-9. | Article | PubMed

34. Pfeifer CS, Ferracane JL, Sakaguchi RL and Braga RR. Factors affecting photopolymerization stress in dental composites. J Dent Res. 2008; 87:1043-7. | Article | PubMed

35. Rees JS, O'Dougherty D and Pullin R. The stress reducing capacity of unfilled resin in a Class V cavity. J Oral Rehabil. 1999; 26:422-7. | Article I PubMed

36. Kleverlaan $\mathrm{CJ}$ and Feilzer AJ. Polymerization shrinkage and contraction stress of dental resin composites. Dent Mater. 2005; 21:1150-7. | Article I PubMed

37. Goncalves F, Azevedo CL, Ferracane JL and Braga RR. BisGMA/TEGDMA ratio and filler content effects on shrinkage stress. Dent Mater. 2011 27:520-6. | Article | PubMed

38. Oberholzer TG, Pameijer CH, Grobler SR and Rossouw RJ. Volumetric polymerisation shrinkage of different dental restorative materials. SADJ. 2004; 59:8-12. | PubMed

39. Bouschlicher MR and Rueggeberg FA. Effect of ramped light intensity on polymerization force and conversion in a photoactivated composite. $J$ Esthet Dent. 2000; 12:328-39. | Article | PubMed

40. Antonucci JM, Liu DW and Stansbury JW. Synthesis of Hydrophobic Oligometric Monomers for Dental Applications. JDR 1993; 72:369. | Website

\section{Citation:}

Mulder R, Grobler SR and Osman YI. Volumetric change of flowable composite resins due to polymerization as measured with an electronic mercury dilatometer.Oral Biol Dent. 2013; 1:1.

http://dx.doi.org/10.7243/2053-5775-1-1 